\title{
Quantification of the role of temporal artery biopsy in diagnosing clinically suspected giant cell arteritis
}

Abstract

Purpose (1) To see the effectiveness of applying the criteria laid down by the American college of Rheumatology in the diagnosis of giant cell arteritis (GCA). (2) To quantify the role of temporal artery biopsy (TAB) in diagnosing GCA using the Greenwich grading system.

Methods A retrospective case notes review of consecutive patients undergoing TAB over 6 years, from 1995 to 2000, in a UK hospital eye unit was done. The American college of Rheumatology 1990 criteria for diagnosis of GCA were applied. A detailed analysis of age of onset, mode of presentation, laboratory findings and histology was done for all the patients.

In an attempt to quantify the clinical value of TAB in patients with clinically suspected

SPR Ophthalmology

Department of

Ophthalmology

Royal Victoria Infirmary

Newcastle upon Tyne, UK

Correspondence:

D Varma

SPR Ophthalmology

Department of

Ophthalmology

Royal Victoria Infirmary

Claremont Wing

Queen Victoria Road

Newcastle upon Tyne NEI 4LP UK

E-mail: deepalivarma@ hotmail.com

Tel: + 44-191-2824410

Fax: + 44-191-2275246

Received: 12 December 2002

Accepted in revised form: 10 June 2003 GCA, the Greenwich grading system was used. The role of TAB was graded as essential, important, helpful, unnecessary, and adverse effect.

Results Out of the 53 patients who underwent $T A B, 13$ were found to have positive TAB, while 40 had negative biopsies. On application of the American College of Rheumatology criteria, 36 patients fulfilled the criteria required to make a diagnosis of GCA. Temporal headache, ESR $>50 \mathrm{~mm} / \mathrm{h}$ and temporal artery tenderness were found to occur more often in patients with positive biopsy.

Conclusion (1) The American College of Rheumatology criteria provide a framework in which the clinician can continually assess the need for TAB. (2) The Greenwich grading system, as applied in evaluating the role of TAB in the management of GCA, demonstrated the clinical usefulness of this invasive procedure in the majority of cases. It
D Varma and D O'Neill

identified the patient groups that benefit the most from a TAB.

Eye (2004) 18, 384-388. doi:10.1038/

sj.eye. 6700677

Keywords: temporal artery biopsy; greenwich grading system; American College of Rheumatology

Introduction

Giant Cell Arteritis (GCA) is a polysymptomatic disease affecting the elderly, with a wide variety of local and systemic clinical manifestations. Onset of symptoms may either be abrupt or gradually progressive, depending on the artery involved. Systemic features include headache, scalp (temporal) tenderness, jaw claudication, malaise, anorexia, weight loss, fever, and arthralgia. These usually precede ophthalmological symptoms. The incidence of ocular involvement in GCA ranges between $14 \%$ and $70 \%$ in different series. ${ }^{1-3}$ A silent or occult presentation has been reported in up to $38 \%$ of the cases. ${ }^{1}$ The most common ophthalmic manifestation of GCA is anterior ischaemic optic neuropathy. Other ophthalmic presenting features include amaurosis fugax and diplopia. Histology of GCA consists of granulomatous inflammation, disruption of the internal elastic lamina, proliferation of the intima, and complete stenosis of the lumen.

Diagnosis of GCA requires the association of multiple factors, but TAB finally establishes the diagnosis. When classic symptoms are present, diagnosis is easily addressed. However, classic symptoms are not always present, and vague symptoms may sometimes be unrecognised by the patient. The clinician should have a high index of suspicion in order to diagnose GCA in the absence of the typical presentation. 
According to the American College of Rheumatology 1990 criteria, ${ }^{4}$ diagnosis of GCA is made when at least three of the following five criteria are met:

1. age at onset of 50 years or older,

2. new onset of localised headache,

3. temporal artery tenderness or decreased pulse,

4. elevated erythrocyte sedimentation rate $(>50 \mathrm{~mm} / \mathrm{h})$ by the Westergren method, and

5. Positive histology findings.

In our study, the effectiveness of the American College of Rheumatology criteria in diagnosing GCA was evaluated and an attempt was made to quantify the role of TAB in the management of GCA using a grading system known as the 'Greenwich grading system'.

\section{Greenwich grading system}

This is a simple method developed by Corbett et al for assessing the value of a clinical investigation. It is designed such that it is easy to use in any clinical situation and applicable to any investigation. The role of the investigation in the management of a given patient is expressed by a single grade: essential (3), important (2), helpful (1), unnecessary (0) or adverse ( -1$)$ (Tables 1 and 2 ). The degree to which an investigation can influence the diagnosis is dependent upon the certainty of the clinician's diagnosis and the certainty with which the investigation can change, make, confirm, or exclude a diagnosis. It is of particular value when it is the only test, which can give the required answer. A test can potentially adversely affect the overall outcome if undertaking it delays a more valuable investigation.

\section{Methods}

A retrospective case notes review of consecutive patients undergoing TAB over 6 years, from 1995 to 2000, in a UK hospital eye unit was conducted. Of the 61 patients who underwent TAB during this period, only 53 case notes could be retrieved. Based on the American college of
Rheumatology 1990 criteria $^{4}$ for diagnosis of GCA, a scoring system was adopted. Each patient was given a scoring of 1 point for each criterion that they met. A diagnosis of GCA was made when they scored a total of at least 3 points. A detailed analysis of age of onset, mode of presentation, laboratory findings, and histology was carried out for all the patients.

In an attempt to quantify the clinical value of TAB in patients with clinically suspected GCA, the Greenwich grading system was used. The impact of a TAB on the management of these patients was assessed in the context of available alternatives. The overall value of TAB in the management of GCA was graded as essential, important, helpful, unnecessary, and adverse effect.

\section{Results}

Case notes of 53 patients who underwent TAB over a period of 6 years from January 1995 to December 2000 were reviewed. Out of these, 13 patients were found to have positive TAB, while 40 patients had negative biopsies. On application of the American College of Rheumatology criteria for the diagnosis of GCA, 36

Table 2 Overall value of TAB in the management of GCA patients

\begin{tabular}{clc}
\hline Grade & Value & Patients $(\mathrm{n}=53)$ \\
\hline 3 & Essential & $11(21 \%)$ \\
2 & Important & $2(4 \%)$ \\
1 & Helpful & $19(36 \%)$ \\
0 & Unnecessary & $21(39 \%)$ \\
-1 & Adverse effect & None $(0 \%)$ \\
\hline
\end{tabular}

Essential: In these patients, only two positive criteria were present (positive $\mathrm{TAB}$ was the third criteria in making the diagnosis).Important: Patients with atypical clinical presentation (where positive TAB was important in making the diagnosis of GCA).Helpful: Three criteria were present (TAB was helpful in confirming the diagnosis).Unnecessary: four criteria were already present; $\mathrm{TAB}$ was unnecessary in these patients as they received steroid treatment on the clinical suspicion (TAB can be negative in upto $20 \%$ patients because of skip lesions) or only one criteria was present and biopsy was found to be negative.Adverse effect: Scalp necrosis etc is one of the reported side effects.

Table 1 Grading system for assessing the value of an investigation in the overall management of a patient

\begin{tabular}{|c|c|c|c|c|}
\hline $\begin{array}{l}\text { Value of the investigation } \\
\text { (grade) }\end{array}$ & $\begin{array}{l}\text { Role of the investigation } \\
\text { in overall management }\end{array}$ & Diagnosis & Investigation & Treatment \\
\hline 3 & Essential & Changed & Only test & Initiated \\
\hline 2 & Important & Made & Replaced others & $\begin{array}{l}\text { Altered } \\
\text { Stopped }\end{array}$ \\
\hline 1 & Helpful & $\begin{array}{l}\text { Confirmed } \\
\text { Excluded }\end{array}$ & Suggested more & $\begin{array}{l}\text { Reassurance } \\
\text { Explanation }\end{array}$ \\
\hline 0 & Unnecessary & No help & $\begin{array}{l}\text { Not altered } \\
\text { Others more use }\end{array}$ & No change \\
\hline-1 & Adverse effect & Incorrect & Delayed others & Incorrect \\
\hline
\end{tabular}


patients fulfilled the criteria required to make a diagnosis of GCA.

In our study, each of the American College of Rheumatology criteria was applied in order to evaluate its validity and its relation to biopsy findings.

\section{Age at onset}

The age distribution of the patients in relation to biopsy findings in this study were as follows:

A (Table 3) total of 53 patients were entered in this study. The mean age at presentation in patients undergoing $\mathrm{TAB}$ was 69 years and the mean age of patients with positive biopsy was 74 years. None of our patients were of Asian or Black ethnic origin.

Applying the American College of Rheumatology criteria, only two out of 53 patients with clinically suspected GCA were less than 50 years of age. In both these patients, the TAB was negative and they did not fulfil the criteria for the diagnosis of GCA. Of the 13 patients with positive biopsy, the age of onset was more than 70 years in the majority of patients. This implies that the more advanced the age the higher the likelihood of GCA.

\section{New onset of localised headache}

Out (Table 4) of 53 patients in the entire cohort, 13 patients had a positive biopsy. The American College of Rheumatology criteria were applied. New onset headache was the presenting symptom in 36 patients. In the remaining patients, presenting symptoms included tender temples, visual disturbances such as amaurosis fugax and visual loss secondary to anterior ischaemic optic neuropathy, and central retinal artery occlusion.

Table 3

\begin{tabular}{lccc}
\hline $\begin{array}{l}\text { Age at } \\
\text { onset (years) }\end{array}$ & $\begin{array}{c}\text { Number of } \\
\text { patients }(\mathrm{n}=53)\end{array}$ & $\begin{array}{c}\text { Positive } \\
\text { TAB }(\mathrm{n}=13)\end{array}$ & $\begin{array}{c}\text { Negative } \\
\text { TAB }(\mathrm{n}=40)\end{array}$ \\
\hline$<50 \mathrm{Y}$ & 2 & 0 & 2 \\
$50-60 \mathrm{Y}$ & 11 & 2 & 9 \\
$61-70 \mathrm{Y}$ & 14 & 1 & 13 \\
$>70 \mathrm{Y}$ & 26 & 10 & 16 \\
\hline
\end{tabular}

Table 4

\begin{tabular}{lccc}
\hline Criteria & $\begin{array}{c}\text { Number of } \\
\text { patients } \\
(\mathrm{n}=53)\end{array}$ & $\begin{array}{c}\text { Positive } \\
\text { TAB }(\mathrm{n}=13)\end{array}$ & $\begin{array}{c}\text { Negative } \\
\text { TAB }(\mathrm{n}=40)\end{array}$ \\
\hline $\begin{array}{l}\text { New onset } \\
\text { of localised } \\
\text { headache }\end{array}$ & 36 & 9 & 27 \\
\hline
\end{tabular}

In all, 10 out of 13 patients with positive biopsy complained of a new onset headache, while the remaining three presented with visual loss. This implies that absence of headache does not rule out GCA as a possible diagnosis.

\section{Temporal artery tenderness}

Of (Table 5) the 53 patients who were included in this study, 29 complained of tenderness over the temporal artery. Out of these, 19 patients had a negative biopsy and 10 patients had a positive biopsy. Three out of 13 patients with positive TAB in the study had a nontender temple with good temporal artery pulsations, suggesting that lack of temple tenderness does not exclude GCA. The majority of patients with positive biopsy had temporal tenderness, implying that tenderness over the temporal artery is a reliable sign of GCA occurrence.

\section{Increased ESR}

In (Table 6) total, 35 of the 53 patients, had elevated ESR. Out of these, 24 patients had a negative TAB and 11 patients had a positive biopsy. Of the 13 patients with positive TAB in the entire study, a majority $(11 / 13)$ of the patients had elevated ESR, although two patients had a normal ESR.

\section{Positive histology}

Of the 53 patients with clinically suspected GCA, positive biopsy was present in 13 patients. Biopsies were considered positive on the basis of the final report issued by the pathologist. Most of the biopsies considered positive had classical histological features of GCA consisting of granulomatous vasculitis with a predominance of mononuclear cell inflammation, usually with multinucleated giant cells.

Table 5

\begin{tabular}{lccc}
\hline Criteria & $\begin{array}{c}\text { Number of } \\
\text { patients } \\
(\mathrm{n}=53)\end{array}$ & $\begin{array}{c}\text { Positive } \\
\text { TAB } \\
(\mathrm{n}=13)\end{array}$ & $\begin{array}{c}\text { Negative } \\
\text { TAB } \\
(\mathrm{n}=40)\end{array}$ \\
\hline Temporal artery tenderness & 29 & 10 & 19 \\
\hline
\end{tabular}

Table 6

\begin{tabular}{lccc}
\hline Criteria & $\begin{array}{c}\text { Number of } \\
\text { patients }(\mathrm{n}=53)\end{array}$ & $\begin{array}{c}\text { Positive } \\
\text { TAB }(\mathrm{n}=13)\end{array}$ & $\begin{array}{c}\text { Negative } \\
\text { TAB }(\mathrm{n}=40)\end{array}$ \\
\hline Increased ESR & 35 & 11 & 24 \\
\hline
\end{tabular}


Applying the American College of Rheumatology criteria to the data from this study, it was noted that out of the 53 patients who underwent a TAB for clinically suspected GCA, positive biopsy was present in 13 patients and hence the diagnosis was confirmed in these patients. GCA was excluded in 15 patients who did not fulfil the American College of Rheumatology criteria for diagnosing GCA and had a negative biopsy. Treatment was altered, that is, steroids stopped following the TAB result in eight patients. All patients with positive biopsy fulfilled the American College of Rheumatology criteria for diagnosing GCA implying that the American College of Rheumatology criteria are of clinical importance in diagnosing GCA.

\section{Application of the Greenwich grading system}

The Greenwich grading system was easy to apply retrospectively in all the patients. The overall value of TAB in the management of GCA was graded as essential, important, helpful, unnecessary, and adverse effect.

Out of the 53 patients reviewed in this study, TAB was noted to be of value in $32(61 \%)$ patients. This figure was obtained by addition of patients in the subgroups 'essential', 'important', and 'helpful' (Table 2). In 21 (39\%) patients ('unnecessary' subgroup) with clinically suspected GCA, TAB was thought to be of no additional value. Either these patients had more than three criteria for the diagnosis of GCA and were treated with steroids regardless of the biopsy findings or there was one or less criterion which therefore made diagnosis of GCA unlikely. In no patient did this investigation adversely affect the clinical outcome.

\section{Discussion}

GCA usually occurs in people older than 60 years with a mean age at presentation of 71 years. Salvarani and co-workers noted that the incidence of GCA increased by $2.6 \%$ every 5 years. ${ }^{14}$ Comparable results were obtained in our study with mean age of patients at presentation being 69 years and in those with positive biopsy the mean age was 74 years. The incidence of GCA was noted to be higher among patients greater than 70 years of age. GCA rarely occurs in Asian and black populations. None of our patients were of Asian or Black ethnic origin. A normal erythrocyte sedimentation rate in patients with biopsy-proven GCA was reported in $8 \%$ of patients by Hayreh $e t \mathrm{al}^{7}$ and $15 \%$ by von Blotzein and Borruat. ${ }^{8}$

In our study, normal ESR was noted in $15 \%$ of biopsy-proven GCA. In agreement with findings in other studies, temporal headache, ESR $>50 \mathrm{~mm} / \mathrm{h}$, and tenderness over the temporal artery were found to occur more often in patients with positive biopsy.

There are few data to guide clinicians in making decisions about treatment when the clinical evidence for GCA is insufficient. Hunder $e t a l^{4}$ developed the American College of Rheumatology criteria 1990 for diagnosing GCA. They compared 214 patients who had this disease with 593 patients with other forms of vasculitis (controls). They concluded that the presence of three or more of these five criteria for diagnosing GCA was associated with a sensitivity of $93.5 \%$ and specificity of $91.2 \%$.

In our study using the American College of Rheumatology 1990 criteria, TAB was seen to be of limited value in altering the course of management when the diagnosis was certain (ie patients with presence of four criteria) and steroids were commenced irrespective of the biopsy findings. In patients where the diagnosis of GCA was probable or possible (ie with presence of two criteria or with atypical presentation), TAB was found to be of increasing benefit. Patients included in the former category belonged to the 'unnecessary' subgroup, and to the essential and important subgroup in the latter (Table 2).

GCA is a systemic disease that can have devastating ophthalmic consequences. Increasing awareness of this disease among clinicians often causes early initiation of treatment with systemic steroids. However, GCA can be incorrectly diagnosed in elderly patients with high ESR and pain in the temporal area. Such an incorrect diagnosis can subject the patient to needless biopsy and the serious side effects of therapy with large doses of systemic steroids. Although uncommon, complications related to $\mathrm{TAB}$ such as postoperative haematoma, scalp necrosis, wound infection, damage to facial nerve, and drooping of eyebrow can occur. $\mathrm{TAB}$ as a diagnostic tool for GCA is not perfectly sensitive, with reported rates of $70-90 \% .^{9}$ The diagnostic value of TAB has been questioned because of low sensitivity. On the other hand, many physicians have emphasised the high value of a positive biopsy before commencing high doses of systemic steroids. TAB is a highly specific invasive investigation for GCA. Positive $\mathrm{TAB}$ confirms the diagnosis, but a negative biopsy does not exclude GCA. This is due to the segmental nature of GCA. Areas of unaffected tissue (skip lesions) are reported in $21-28 \%$ of cases, ${ }^{10}$ leading to a $5-61 \%$ incidence of false-negative biopsies. ${ }^{10,11}$ Several methods have been proposed to increase the diagnostic accuracy of TAB such as removing a longer segment of artery or taking a contralateral biopsy specimen.

Furthermore, the selection of the biopsy site by palpation, 
angiography, or Doppler and multiple sectioning of the specimen have been proposed. Thus in many cases, the diagnosis has to be established upon certain clinical features and laboratory findings, which help clinicians to differentiate GCA from other disorders. Some physicians feel that a high rate of false-negative biopsies diminishes the value of the procedure and there remains some controversy about its therapeutic impact.

In order to improve the efficiency of the service and decrease rates of inappropriate referral for any investigation, it is important that only patients in whom real diagnostic uncertainty exists are referred. Various workers have studied the diagnostic value of $\mathrm{TAB}$ and its cost effectiveness. There are different opinions about the usefulness of a TAB in patients with clinically suspected GCA. Vilaseca $e a^{12}$ assessed the diagnostic usefulness of TAB in GCA. They performed a retrospective study of the biopsy specimens and clinical features of 103 patients who had undergone TAB over 14 years. They concluded that using criteria proposed by Ellis and Ralston, TAB reached a diagnostic sensitivity of $81.8 \%$, with a positive predictive value of $90.2 \%$. Skaug $e a^{13}$ also studied the clinical usefulness of a TAB in diagnosing GCA. They concluded that the high frequency of negative results of $\mathrm{TAB}$ performed as a routine procedure in patients suspected of GCA justifies further research regarding an improvement of the sensitivity of this test or the development of other tests with better predictive values.

Using the American College of Rheumatology criteria 1990 for diagnosis of GCA in our study, TAB was found to be $100 \%$ specific (ie those with a positive biopsy and also fulfilled the criteria required for GCA diagnosis) and reached a positive predictive value of $100 \%$.

\section{Significance of the Greenwich grading system in our study}

In our study, using the Greenwich grading system, a comparison of the value of TAB in different groups of patients was carried out to determine those in whom referral for biopsy was the most or least appropriate. The Greenwich grading system helped in identifying the patients with clinically suspected GCA who benefit most from a TAB. This included patients in the 'essential' and 'important' subgroup (Table 2). We feel this will reduce inappropriate $\mathrm{TAB}$ referrals and provide assistance to clinicians in deciding the need for a TAB. To the best of our knowledge, the quantification of the role of TAB in the management of GCA using the Greenwich grading system has not been done before.

\section{Conclusions}

1. The American College of Rheumatology criteria provide a framework in which the clinician can continually assess the need for TAB. This would promote good practice and ease the clinical dilemma for diagnosis of GCA.

2. The Greenwich grading system, as applied in evaluating the role of TAB in the management of GCA, demonstrated the clinical usefulness of this invasive procedure in majority of the cases.

3. The Greenwich grading system identified the patient groups, which benefit most from a temporal artery biopsy.

\section{References}

1 Hayreh SS, Podhajsky PA, Zimmerman B. Ocular manifestations of giant cell arteritis. Am J Ophthalmol 1998; 125: 509-520.

2 Ghanchi FD, Dutton GN. Current concepts in giant cell (temporal) arteritis. Surv Ophthalmol 1997; 42: 99-122.

3 Gur H, Rapman E, Ehrenfeld M, Sidi Y. Clinical manifestations of temporal arteritis: a report from Israel J Rheumatol 1996; 23: 1927-1931.

4 Hunder GG, Bloch DA, Michel BA, Stevens MB, Avend WP, Catabrese LH et al. The American College of Rheumatology 1990 criteria for the classification of Giant cell arteritis. Arthritis a Rheum. 1990; 33(8): 1122-1128.

5 Corbett MC, Shilling JS, Holder GE. The assessment of clinical investigations: The Greenwich grading system and its application to electro diagnostic testing in ophthalmology. Eye 1995; 9: 59-64.

6 Jose L. Tovilla-Canales. Ocular manifestations of giant cell arteritis. Curr Opin Ophthalmol 1998; 9: 73-79.

7 Hayreh SS, Podhajsky PA, Raman R, Zimmerman B. Giant cell arteritis: validity and reliability of various diagnostic criteria. Am J Ophthalmol 1997; 123: 285-296.

8 Von Blotzein SG, Borruat FX. Arterite a cellules geantes et vitesse de sedimentation normale: plus que'une exception. Klin Monatsbl Augenheilkd 1996; 208: 397-399.

9 Mizen TR. Giant cell arteritis: diagnostic and therapeutic considerations. Ophthalmol Clin North Am 1991; 4: 547-556.

10 Wells KK, Folberg R, Goeken JA, Kemp JD. Temporal artery biopsies: cor-relation of light microscopy and immunofluorescence microscopy. Ophthalmology 1989; 96: 1058-1064.

11 Weyand CM, Bartley GB. Giant cell arteritis: new concepts in pathogenesis and implications for management. Am J Ophthalmol 1997; 123: 392-395.

12 Vilaseca J, Gonzalez A, Cid MC, Lopez-Vivancos J, Ortega A. Clinical usefulness of temporal artery biopsy. Ann Rheum Dis. 1987; 46(4): 282-285.

13 Skaug TR, Midelfart A, Jacobsen G. Clinical usefulness of biopsy in giant cell arteritis. Acta Ophthalmol Scand. 1995; 73: 567-570.

14 Salvarani C, Gabriel SE, O'Fallon M, Hunder GC. The incidence of giant cell arteritis in Olmsted county, Minnesota: apparent fluctuations in a cyclic pattern. Ann Intern Med 1995, 123: 192-194. 